\title{
Is Family Decision-Making Power?
}

\author{
Joanna R. Pepin \\ University of Maryland
}

\begin{abstract}
Do 'final say' survey questions measure power within families? Researchers rely on these items as proxy indicators of gender inequality within households, although there are reasons to doubt decision-making is equated with power. I review relative resources and exchange theory predictions about decision-making and two potential moderators: the gender system and methods of allocating income. Using original data $(n=3,975)$ from a vignette-survey experiment to disentangle the mechanisms leading to decision making authority, I find higher relative earners within families are not regarded as entitled to the final word in decisions. Whether respondents considered earnings individually or community owned did not explain the lack of association between financial resources and decision-making clout. Findings show a significant association between the decider's gender and perceptions of fairness: specifically, when women were presented as the decider over monetary family choices, unilateral decision-making was viewed more favorably. Results from the qualitative analysis of the reasoning behind these evaluations were consistent with beliefs in egalitarian essentialism, that women and men are equal but characteristically different. Findings suggest 'final say' measures should be interpreted cautiously as markers of power and offers insights into why gender equality within families remains stalled.
\end{abstract}

Keywords: gender inequality, family, power, household finances, survey methods

Acknowledgements: Data for this project were collected by Time-sharing Experiments for the Social Sciences (TESS), NSF Grant 0818839. I thank the TESS Principal Investigators, Jeremy Freese and James Druckman, and anonymous grant reviewers for their suggestions. 
Final Say

\section{INTRODUCTION}

In 2008, Pew Research Center proclaimed public consensus that women were the decision makers in the home (Pew Research Center 2008). Drawing on classic research by Blood and Wolf (1960), the assumption in Pew's declaration was that women hold more power than men within families because they are more likely to be seen as the final decision makers over home matters. Blood and Wolf's research generated a steady stream of empirical analyses using decision making as the primary indicator of power within family relationships, although there are reasons to suspect final decision making may not function as a proxy measure for power (HsiaoLi 2010). Among many shortcomings, a central critique of "final say" measures is that they fail to capture processing power - identifying who leads the conversation, presents the options, changes their partner's mind, and deems decisions as valuable and worthwhile (Galliher et al. 1999; Hsiao-Li 2010; Simpson et al. 2015; Thibaut and Kelley 1959). Power may be a dominant research topic but definitions of power are varied and measurements of power within families are not well validated (Blumberg and Coleman 1989; Farrell, Simpson, and Rothman 2015; Mizan 1994), making assessing gender inequality within families challenging.

To investigate whether power is characterized in final say over family decisions, researchers have explored the mechanisms of decision-making. Employment, earnings, and gender ideology have all been identified as key sources of power, but how these mechanisms interact to manifest in decision making authority is not well established (Blumberg and Coleman 1989). Complicating matters, these characteristics are often regarded as proxy measures of power themselves, despite a lack of empirical testing. To address these shortcomings, this study identifies the sources and reasoning processes behind the outcomes of commonly used "final 
Final Say

say" survey measures, questioning the assumption that decision making authority is a proxy for power.

In this paper, I adopt Weber's definition of power, the ability to enforce one's will even against resistance (Komter 1989). Using a mixed-methods approach, I isolate sources of decision-making authority by using original data from a vignette-survey experiment collected from a national sample of U.S. adults. Using an experiment to examine the sources of decisionmaking authority is advantageous for two reasons. First, isolating the effects of multiple power bases within the population is difficult given the non-randomization of the co-occurrence of variables of interest. For example, it is challenging to separate power stemming from gender norms from power derived from higher financial contributions when breadwinning often coincides with male dominance. Second, people's justifications of their own behavior reflects a mixture of attitudes, circumstance, context, and other factors (Cherlin 2009), whereas opinions of others may better estimate normative values.

I begin by using relative resource theory to predict beliefs about entitlement to decision making, that as partners bring increasing resources home, they gain power within their families. I then turn to two potential moderators of relative resources' explanatory power: the gender system and methods of allocating financial resources within families. To do so, respondents were presented with a hypothetical couple that varied by their relative earnings and the gender of the fictional decider. Respondents reported how they thought the fictional couple should share their income and indicated their perception of fairness in a hypothetical decision. To attend to the reasoning behind these mechanisms, I conclude with a critical discourse analysis of respondents' short answer explanations for their fairness perception, revealing the patterns in the logic behind decision-making authority. 
Final Say

\section{BACKGROUND}

In Blood and Wolfe's (1960) classic study, individuals with incomes larger than their partner's earnings generally held decision making authority, consistent with resource and exchange theories that explain men's family power as a function of their greater monetary contribution to the household (Becker 1974; Coltrane 1996; Ferree 1990). For example, breadwinning men often have the last word about family financial decisions and more often spend ostensibly shared money without consulting their partners (Burgoyne et al. 2006). Given this association, having greater entitlement to final say on family decisions was interpreted as one expression of power. Increases in women's waged work were expected to increase women's bargaining power within the family, as they contribute more to the common pot (Bittman et al. 2003; Brines 1994). Indeed, women have gained some influence in family decision making and increased control of family money as the difference in their relative incomes diminished (Belch and Willis 2002; Kenney 2006).

If relative resources are a primary source of power, we should find no gender differences in the higher earner's ability to convert their earnings into decision making authority. Yet, extant research documents women's challenges in gaining greater power within the family, despite their increased financial contributions (Townsend 2002). For example, economic dependence arguments have largely been unable to explain persistently unequal household labor division between men and women (Gupta 2007). As the relative earnings of couples converge, informal ways of sustaining inequality between men and women become apparent (Komter 1989). Below, I detail two potential mediators of women's ability to translate increased earnings into power within their families: the gender system and methods of allocating financial resources. 
Final Say

\section{Gender System}

Breadwinning wives do not seem to convert their higher-earning status into power to the same extent as men (Blood and Wolfe 1960; Blumstein and Schwartz 1983; Burgoyne 2004; Burgoyne et al. 2006; Hochschild and Machung 1989). Women’s wages are often assigned different meanings than men's wages, weakening women's ability to translate their earning into power within their relationships (Pyke 1994). In some instances, women control household expenditures, but men control the inflow of household money and maintain veto power (Hsiao-Li 2010). Although women may appear to have increased power as evidenced by their management of family budgets, their control over surplus income may be a better indicator of power than the allocation of resources for basic necessities (Blumberg and Coleman 1989).

The gender system, processes that define men and women as significantly different from one another, may account for the lackluster ability of relative resource theories to explain persistent gender inequality within families (Ridgeway and Smith-Lovin 1999). Men may be viewed as the head of the household, ultimately harnessing power in families no matter their relative contribution to the family's income. Some women refrain from viewing their earnings as entitling them to power (Burgoyne 2004; Burgoyne et al. 2006) and some couples intentionally preserve men's power within families (Tichenor 1999). Breadwinning women sometimes minimize their financial dominance intentionally in order to protect the masculinity of their partners (Brines 1994; Pyke 1994). Commitment to conventional gender ideology may account for men's tendency to hold power over decisions having little to do with money, such as deciding on shared leisure activities (Blumstein and Schwartz 1983; Schwartz 1994). If this is the case, and decision making represents power, it would be expected that men will be seen as entitled to final decisions over family matters, irrespective of their relative earnings. 
Final Say

Alternatively, it is possible that adherence to egalitarian essentialism, that men and women are equal but inherently different, results in beliefs that women hold decision making authority over family matters (Cotter, Hermsen, and Vanneman 2011). Consequently, family decisions may be seen as fundamentally in women's domain, no matter her earnings. Whether or not women's family decision making is indicative of power is not straightforward. Although decision making may be construed as power, responsibility for family decisions may reflect an endless second shift for women (Hochschild and Machung 1989; Walzer 1998). Moreover, decision making authority may not indicate power if women are expected to make choices that center decisions on the concerns and interests of their male partners (Blumberg and Coleman 1989; Komter 1989).

\section{Financial Allocation Strategies}

Resource theories fail to take into account what happens to individual income once it enters households (Kenney 2006; Roman and Vogler 1999). In addition to assuming family decision making represents power, assumptions that increases in women's relative earnings are translated into greater say over the household presume family members combine money into a common pot. Thus, we might expect women to be able to translate their earnings into power, only if the assumption is met that couples are pooling their earnings.

Women's labor force participation is associated with decreases in sharing financial resources (Kenney 2006). While women may be closing the gap in absolute earnings, they are not necessarily increasing the amount of earnings they deposit into a shared pot, diminishing potential advances in entitlement to say over family matters. In anticipation of difficulties translating earnings into power once money becomes shared, some women keep their earnings separate as a way to maintain individual control over them (Bennett 2013). For example, women 
not currently in the labor force report they expect to keep future earnings separate once they reenter the labor market (Burgoyne 1990). When couples keep some or all money separate, we might not see any differences in women's decision making authority based on their relative earnings to their partner. Some evidence suggests keeping money separately is associated with male dominance (Vogler and Pahl 1994). Consequently, if decision making is equated with power, women's decision making authority may be weakened when income is thought to be an individual resource.

\section{DATA AND METHODS}

I draw on original data from a nationally representative dataset supported by Timesharing Experiments for the Social Sciences (TESS) (Freese and Druckman 2016). Respondents were recruited by GfK, which fielded the survey in July and August of 2016. A total of 4,020 respondents participated in the survey, which represents a response rate of 60.3 percent. The analytic sample was meant to closely parallel the demographics of the United States. I use sample weights in all analyses to correct for any misrepresentation of the US population but the results are consistent with or without the weights. Three respondents selected contradictory responses across two survey questions and were subsequently excluded from the analysis. ${ }^{\mathrm{i}}$ I used list-wise deletion in the analyses, resulting in 42 deleted observations for a total sample size of 3,975 respondents. I present the weighted descriptive statistics for key demographic variables of the sample in Table 1.

\section{Experimental Design}

Respondents were randomly assigned to one of twenty-four vignettes. The vignette design used a two-by-two-by-three-by-two factorial design, resulting in roughly equal number of respondents viewing each of 24 different vignettes (summarized in Figure 1). Vignettes were 
systematically varied by key characteristics that influence relationships: relative earnings, marital status, parental status, and relationship duration. ${ }^{\text {ii }}$ In each condition, respondents were told that they would be presented with a hypothetical scenario and would be asked to give their opinion of how a couple should handle money. The 3-year married parents, male breadwinner vignette read, for example (italics show manipulated conditions):

Michelle and Anthony, both 31 years old, are married and have been a couple for 3 years. They enjoy spending time together and they are happy with their relationship. They have one child together. Although they both work about forty hours per week, Anthony earns \$2,800 a month while Michelle earns \$1,200 a month.

To test the resource and exchange theory, I manipulated the relative income of the fictional couple, the gap between men's share and women's share of the family's earned income. Dollar amounts of earnings were based on analysis of median total household income $(\$ 53,657)$ calculated from the 2014 American Community Survey (DeNavas-Walt and Proctor 2015). This estimate was rounded down to make comparisons of earnings more interpretable for respondents and to represent the lower earner as making just over the federal minimum wage. By varying whether the higher earner is a man or woman, I tested whether breadwinning ideology is conditional on gender.

As shown in the vignette example, other characteristics of the fictional couple were indicated in the vignette in order to address potentially confounding variables. To hold constant time in paid labor, each person in the couple was shown as working forty hours per week. The fictional couples were presented as 31 years of age which is a little older than the average age of first marriage and the age is consistent with timing of first births (Cohen 2014). This age was selected because it limits potentially unintended assumptions related to later life stages such as retirement and children from previous relationships. Racially neutral names, Anthony and 
Final Say

Michelle, were chosen because they were the most popular shared names for Black and White babies born about thirty years ago (Lieberson 2000). ${ }^{\text {iii }}$

\begin{tabular}{ll} 
Condition \#1 & 1. Married \\
Relationship Status & 2. Living together \\
\hline Condition \#2 & 1. No children \\
Parental Status & 2. One child together \\
\hline
\end{tabular}

1. Although they both about forty hours per week, Anthony earns \$2,800 a month while Michelle earns \$1,200 a month;

Condition \#3

Relative Earnings
2. Although they both about forty hours per week, Michelle earns $\$ 2,800$ a month while Anthony earns \$1,200 a month;

3. They both work about forty hours per week, and each earn $\$ 2,000$ a month.

\section{Condition \#4}

Relationship Duration
1.3 years

2. 7 years

Figure 1. Experimental Design

I began the experiment by asking respondents to indicate how they thought the fictional couple they were presented with should allocate their income. Specifically, respondents were asked, "Do you think Michelle and Anthony should: (a) Have a shared account in which they both deposit all their earned income; (b) Keep all their earned income in separate, individual accounts; or (c) Have both a shared account and separate, individual accounts? This measure was adapted from behavioral measures used in surveys such as the International Social Survey Program, Fragile Families and Child Wellbeing Study, and the National Longitudinal Study of Adolescent Health to evaluate how couples organize their finances (Brooks-Gunn et al. 2011; Harris et al. 2009; ISSP Research Group 2014). The answers to this question were subsequently used as the financial allocation predictor variable.

Next, respondents were asked to evaluate the fairness of the hypothetical decision making of couples in fictional vignettes. Respondents were informed the couple has to make a decision about purchasing one of three different items: 1) which house or apartment to take; 2) what 
Final Say

mattress to buy; or 3) where to go on vacation. These items were selected because they are items that, in theory, each person in a couple might care equally about. Respondents were told that although the couple talked this over and they care equally about the decision, one of them ultimately decides since they can't agree. To test perceptions of gender, the survey systematically varied who was shown as ultimately making the decision (Michelle or Anthony) and then asked how fair they thought it was that person made the decision. Perceptions of fairness were measured on a four point scale: 1 . Very fair; 2. Somewhat fair; 3. Somewhat unfair; and 4. Very unfair. Although pilot testing of the survey showed most respondents wanted a choice to indicate the couple must make the decision together, the survey was purposefully designed so that "equal input" was not an option in order to better measure perceptions of influence. To facilitate the presentation of results and to ease comparison, the scale is presented as a binary measure. ${ }^{\text {iv }}$ Answers were re-coded to combine "very fair" and "somewhat fair" (1) and "somewhat unfair" and "very unfair (0) $)^{\mathrm{v}} . "$

Next, to test differences in perceptions of monetary decisions and non-monetary ones, respondents were subsequently asked their opinion about the fairness of deciding about an activity, either shared weekend activities or what movie to go see ${ }^{\mathrm{vi}}$. Specifically, I asked: "Most of the time Anthony and Michelle make a decision together about "shared weekend activities"/ “what movie to go see." In instances when they can't agree, most of the time "Anthony"/ "Michelle" eventually accepts "Michelle's"/ "Anthony's" opinion. How fair do you think this is?" The same fairness scale was used as described above.

A predictor variable was constructed to test whether the gender of the decider and the pattern of decision making jointly influence perceptions of fairness. If the respondent was assigned a vignette showing the same person (Michelle or Anthony) ultimately making both the 
item and activity decision, they were coded as receiving the "same" (1) vignette condition. For respondents who received a vignette in which the man or woman made the item decision and then the opposite person was presented as making the activity decision, they were coded as receiving the "different" $(0)$ vignette condition.

To summarize, the two primary dependent variables are dichotomous measures of the perception of fairness when one person in a fictional couple ultimately makes a decision about an item and a shared activity. The contribution of this article is to explore how relative earnings, gender norms, and the allocation of financial resources impacts perceptions of decision making within families. To measure the influence of relative earnings, respondents were randomly assigned a vignette in which the fictional man was the higher earner, the couple made relatively the same amount of income, or the fictional woman was the higher earner. The gender of the decider in the fictional couple (Michelle or Anthony) was manipulated to test gender norms. To understand how perceptions of shared or independent ownership of earnings moderate the effects of relative earnings, respondents were asked to indicate if the hypothetical couple should share all, none, or some of their income. I also included a binary measure to test whether the pattern of decision making and gender of the decision maker interact to influence perceptions of fairness. To further explore the reasoning behind these mechanisms, in an open-ended question, I asked respondents to explain why they indicated this level of fairness. To analyze this data, I conducted a critical discourse analysis (Fairclough 1995), beginning with an emergent coding strategy and using a constant comparative approach to organize recurring reasoning (Corbin and Strauss 2008). Initially, I reviewed a random sub-sample of 100 responses and inductively organized them into mutually exclusive categories. I then systematized my procedures by generating coding rules and definitions to follow for the remainder of the analysis, creating new 
Final Say

categories as patterns developed. In instances where respondents used multiple logics to explain their standpoint, I systematically assigned the response to the first explanation the respondent provided. To ensure reliability of the codes, I plan to enlist a peer coder to randomly code a subset of responses to compare agreement in coding procedures. To date, 10 percent of the shortanswer responses related to the item decision have been coded. In the next couple of months the remaining short-answer responses will be coded and I will undertake a similar procedure for the responses related to the activity decisions.

\section{RESULTS}

Table 2 presents the results showing perceptions of fairness by the primary variables of interest and the vignette manipulations. The first three rows of the table shows no substantial difference in perceptions of fairness by the relative earnings of the fictional couple. Moving down the table, about 62 percent of respondents who were told the fictional woman made the item and activity decisions indicated the decision was fair. Comparatively, the next row of the table shows only 46 percent of respondents indicated the item decision was fair when shown the fictional man making the decision but that 71 percent of respondents thought the activity decision was fair when the man was shown as the decision maker. There are no substantial difference in perceptions of fairness by the financial organizational strategy respondents chose for the fictional couple. With the exception of when a woman is shown as making the decision, across vignette manipulations, respondents were more likely to perceive the decision as fair when responding to the activity decision compared to the item decision.

[Insert Table 2 about here]

Next, to test for the statistical significance of the descriptive associations described above, I present the results from the logistic regression analyses in Table 3. Models include the 
demographic characteristics of respondents shown in Table 1 and the vignette manipulations not central to these analyses. The first three models show the perceptions of fairness when the decision being decided was an item and the remaining four models (Models $4-7$ ) present the results of perceptions of fairness in the follow-up decision about a shared activity. The model outcomes are shown as odds ratios, meaning that numbers greater than one indicate higher levels of fairness in the decision compared to the reference group and numbers less than one represent less agreement the decision was fair comparatively.

Overall, results from the logistic regression analyses shown in Table 3 reflect the descriptive evidence reviewed in Table 2. Across the models, results reveal the gender of the presented decider influences perceptions of decision making. The first three models have a coefficient less than one, meaning when the man was presented as making the decision about an item, respondents were statistically less likely to evaluate the decision as fair compared to respondents who were shown the scenario in which the woman made the item decision. Comparatively, the follow-up question about deciding on a shared activity show respondents were more likely to evaluate the decision as fair when the decider was shown as a man. Models 2 and 5 include the relative earnings manipulation and the interaction of the gender of the decider with the relative earnings for the item and activity decisions. I find no significant differences by relative earnings or with the interaction, suggesting perceptions of fairness in decision making do not vary systematically by the relative earnings of couples.

\section{[ Insert Table 3 about here]}

Figure 2 presents the predicted probability of viewing the decision as fair by the gender of the fictional decider and the relative earnings of the couple for the item and activity decisions. Probabilities are based on Model 3 (item) and Model 6 (activity) of Table 3. Comparing the first 
three light grey bars shows little difference in perceptions of fairness by relative earnings when women were shown as the decision maker, averaging about 62 percent of respondents viewing the decision as fair. When told the decider was the man, the light grey bars show the decision was viewed as less fair, with less than half of respondents indicating the decision was fair across relative earnings conditions. Looking at the dark grey bars, decisions about shared activities similarly show little variation by the relative earnings of the fictional couples. Interestingly, in the case of shared activities, the second decision respondents were face with, perceptions of fairness were higher when the decider was shown as a man than as a woman. Together, the results suggest the relative earnings of the fictional couple does not substantially influence the probability that respondents viewed the decision as fair. Interestingly, the gender of the presented decider does seem to matter to perceptions of decision making fairness, although in opposite directions depending on the decision.

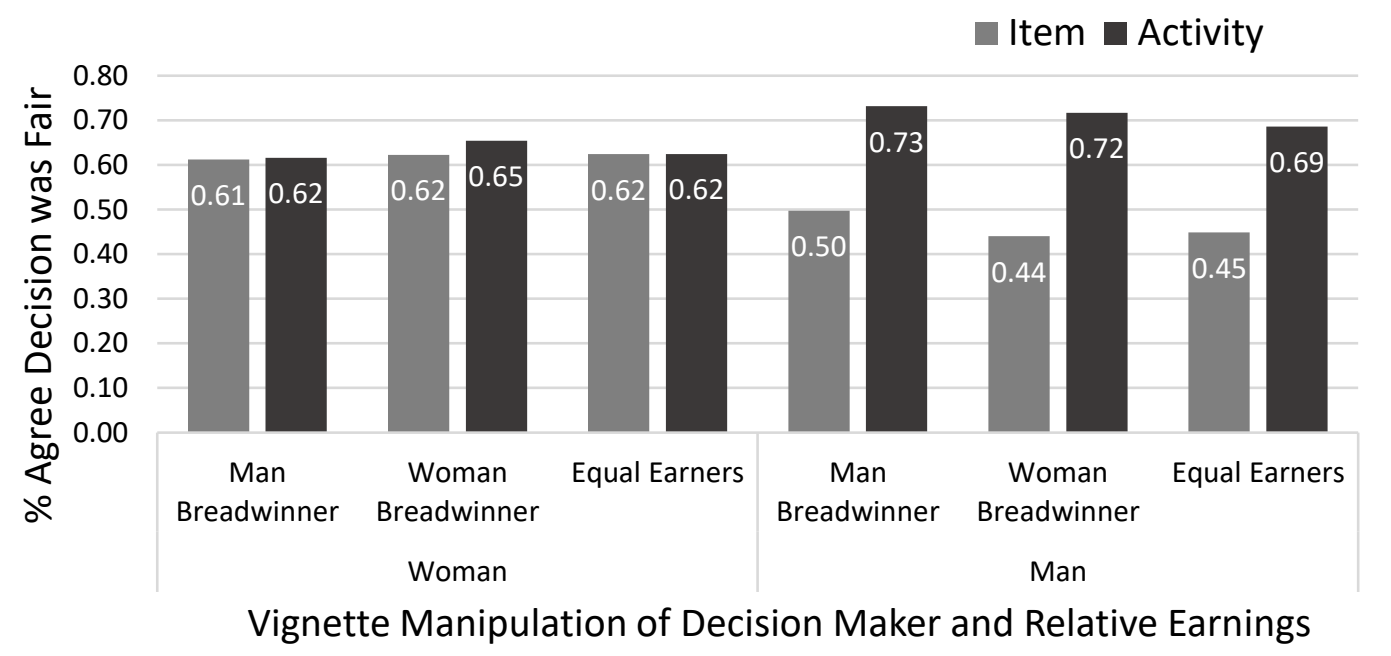

Figure 2. Predicted Probability of Perceived Fairness in Decision Making by Type of Decision

I added the allocation strategy selected for the fictional couple to test whether the lack of association between fairness perceptions and relative earnings is explained by the organizational strategy (Models 3 and 6). I find only minimal support for the hypothesis that financial organizational strategies are associated with perceptions of decision making. When respondents 
were presented with an equal-earning couple and selected both shared and separate accounts compared to only shared accounts, item decisions were less likely to be seen as fair. There were no other statistically significant differences associated with perceptions of fairness over decisions related to the organizational strategy selected for the couple.

Model 7 suggests that the pattern of decision making matters to perceptions of fairness. Counter intuitively, when the gender of the decider was the same for both the item and activity decisions, respondents were more likely to perceive the decision as fair, compared to when the decider was rotated. As shown in Figure 3, when the gender of the decider was the same for both the first and second decision, respondents were more likely to agree the second decision was fair. This pattern was true regardless of whether the decider was presented as a woman or a man in both cases. However, when the second decision was shown as decided by a man, respondents were more likely to agree the decision was fair whether the woman or the man made the first decision. The results point to intriguing reasoning behind the gendered nature of decisions.

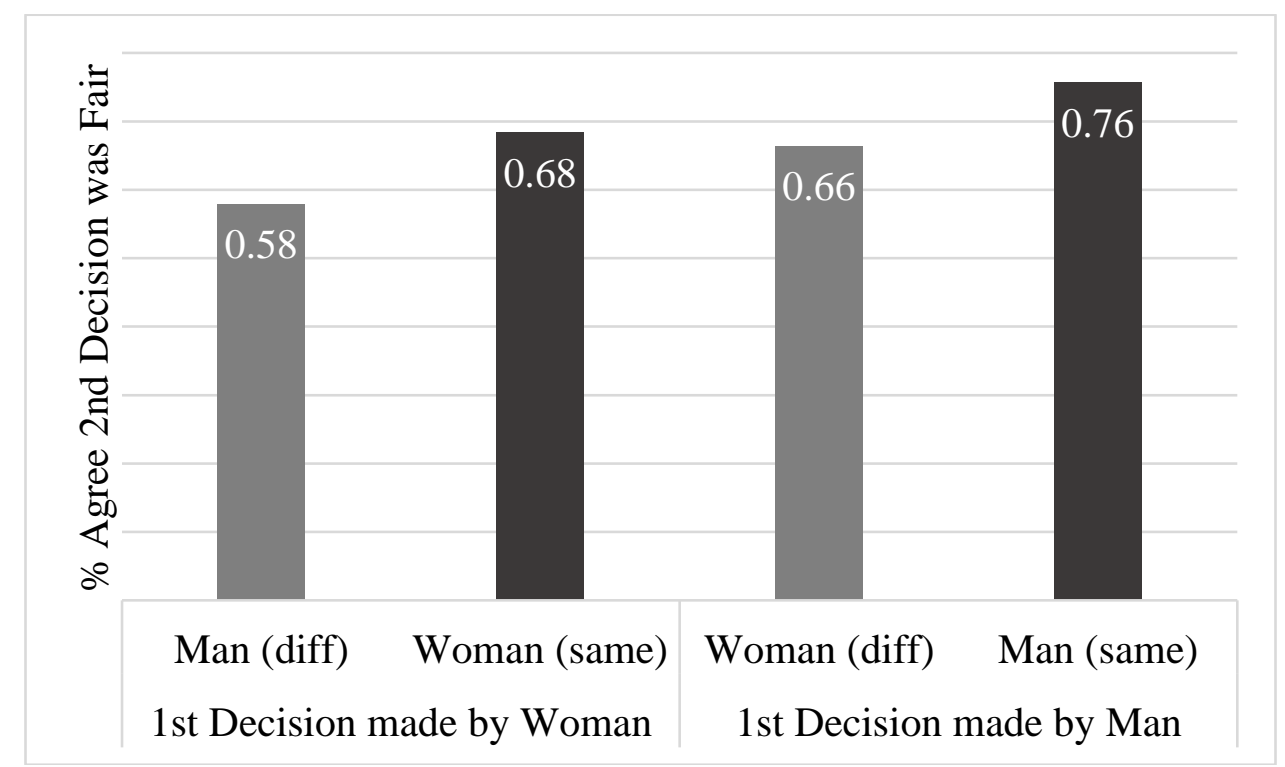

Figure 3. Predicted Perception of Fairness of Activity Decisions by Gendered Order of Decider.

The critical discourse analysis of the short-answer responses respondents gave describing their reasoning for their fairness perspective produced six master categories: Equality or Bust; 
'Has to be Made'; Gender Trumps All; \$ Talks; Item Dependent; and Giving In is a Decision.

The remaining respondents did not follow logic that was easily categorized into a similar group, their answer was unclear, or the respondent did not provide an answer. The most frequently provided reasoning suggested respondents evaluated the fairness of the decision on whether it was made jointly and equally (Equality or Bust). In 94\% of these answers, the respondent rated the decision as unfair. In the other $6 \%$ of cases, the respondents seemed to reference their decision to rate the decision as "somewhat fair" as opposed to "very fair." Although this was the most popular reasoning provided no matter the gender of the fictional decider, it was offered to a greater extent when the man was presented as the decider than when the woman was the portrayed decider (.41 and .28 respectively). Many of these respondents argued that no decision should be made until the couple reached consensus and compromising was suggested repeatedly.

In a seemingly opposite perspective, the second most frequently cited explanation was that a 'Decision Had to be Made.' Over $96 \%$ of respondents who used this reasoning evaluated the decision as fair. Respondents using this logic assumed that without someone making a decision, the couple would miss out on whatever the purchase was. Although some respondents insisted they would have said it was fair if the other person similarly unilaterally decided, this type of reasoning was more frequent when the woman was presented as the decider.

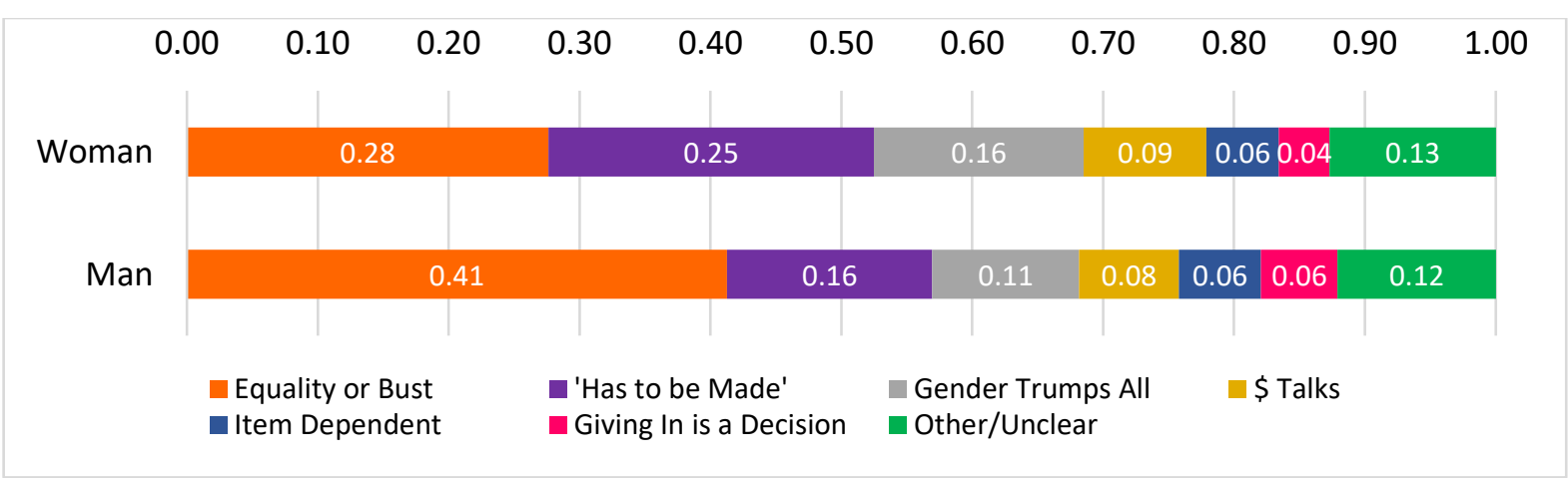

Figure 4. Reasoning Behind Perceptions of Fairness in Decision Making (\%) 
Final Say

More people argued that gender of the decider (Gender Trumps All) was more important than money than the opposite, and this was mostly true when the woman was the fictional decider. The gender of the fictional decider was associated with two competing arguments: Head of Household and Happy Wife. Respondents arguing Head of Household logic either said the decision was fair when the fictional man made the decision or unfair if the fictional woman made the final decision. These respondents were most likely to reference the bible in their statements. In contrast, respondents cited women as ultimately being entitled to the final decision for a diversity of reasons. Some of these respondents argued that home decisions are a woman's domain. Others suggested that women are more likely to have to conduct the unpaid labor surrounding the purchase (planning the vacation or cleaning the household) and thus are entitled to greater say. Others said the decision was fair when women make the decision by stating "happy wife, happy life," a nod and wink phrase about women's power in relationships. Still others suggested the decision was something that women care more deeply about that men, despite the vignette prompt that both members of the couple cared equally about the decision they faced. Interestingly, these polarized arguments about men and women's entitlement to final decision making were used about equally.

In about equal frequency, and less often than appeals to gender, respondents argued that greater earnings entitled someone to final say over the item decision. It could be that inclusion of the equal earning vignette muted this reasoning compared to gender appeals, but even when excluding the equal earners vignette, respondents cited the gender of the fictional earner more frequently than the relative incomes of the fictional couple when evaluating the fairness of the decision. In about equal measures, respondents used logic that pulled directly on the item in question being presented or argued that giving in by the fictional person was itself a decision. 
Final Say

\section{DISCUSSION AND CONCLUSIONS}

A substantial stream of research on inequality within families use 'final say' survey questions to analyze power in relationships even though using decision making authority as a proxy for power is questionable (Galliher et al. 1999; Hsiao-Li 2010; Simpson et al. 2015; Thibaut and Kelley 1959). In this paper, I investigated the sources and reasoning processes behind these "final say" survey indicators to better understand when and if decision making authority indicates power in relationships. If 'final say' characterizes power, relative resource and exchange theory suggests that individuals with incomes larger than their partner's earnings will be evaluated as entitled to greater decision making authority (Becker 1974).

Findings show no significant difference in perceptions of fairness based on the relative earnings of the fictional couple. In fact, respondents were primed to think about money because they were asked to evaluate how a fictional couple should share financial earnings before responding to questions about decision making. Despite this, relative earnings of the fictional couple were not statistically significant in any of the models and the qualitative analysis shows money was not a predominate justification used when describing evaluations of fairness. The empirical analysis also showed that conceptions of money as individually or shared had little influence on perceptions of fairness in decision making. In other words, how money is allocated within households does not appear to moderate the lack of explanatory power of relative

resources and exchange theories. These results suggest that if 'final say' authority represents power, the power source is not derived through economic contributions to the household.

I also reviewed arguments that gender may be a primary source of decision making authority. In doing so, I presented two competing perspectives about how gender norms may influence the perception of fairness in decision making. On the one hand, men may wield 
decision making authority if they are considered the "head of households." On the other hand, beliefs in egalitarian essentialism, that women and men are inherently different but equal, may result in normative support for women's entitlement to decisions about family and home matters. Findings reveal that the gender of the fictional decider mattered substantially to people's perceptions of fairness. Decisions about items were more likely to be viewed as fair when women were presented as the decider. Comparatively, women's decision making authority was not evident in follow-up decisions about activities, when decisions made by men were evaluated more positively.

These findings demonstrate that power differentials in couples are not fully explained by income differentials, whereas identity and family processes are important dimensions to investigate (Moore 2008). Results add to evidence that decisions affecting families are predominately believed to be women's responsibility. More people questioned the fairness of item decisions when the man was presented as the decider, whereas women's item decisions were more likely to go unchallenged, reporting a decision just 'Had to be Made.' What this data can't resolve is whether men are viewed as having an interest in these decisions but are not entitled to it, or whether the decisions affecting families are trivialized in ways similar to the devaluation of predominately female occupations (Hsiao-Li 2010). If men aren't interested in family decisions, is women's decision making authority really indicative of power (Komter 1989)?

The next step in this analysis is to explore the reasoning behind the perception of fairness in the follow-up questions about shared activities. Whether respondents were attuned to the difference in the type of decision or the pattern of decision making is currently unclear. 
Are perceptions of decision making influenced by other relationship dynamics? The quantitative findings suggest respondents were not using trade-offs as a benchmark for their evaluation given that when one person was shown as making both decisions respondents rated it as more fair. A more persistent limitation of this study is that it cannot evaluate processing power, the ability of partners to lead conversation and control what and how decisions are discussed. For example, pleas for joint decision making don't describe who is likely to ultimately compromise or whether both partners are expected to contribute equally to arrive at a decision (Hsiao-Li 2010). Future research may consider perceptions of fairness regarding personal spending money. It would be interesting to evaluate how gender influences who is seen as entitled to make unilateral decisions about spending for personal items.

I began this paper asking whether 'final say' survey questions measure power within families. Findings show no definitive support that decision making is a proxy for power. Although some may argue that results suggest normative support for women's power over family matters, the processes behind the social consensus in women's decision making authority may reflect a necessity brought about the unequal social conditions in which family relationships operate (Gramsci 1971). Beliefs in the gender system were intransigent, as resource-advantaged women were no more or less likely to be seen as ultimately responsible for family decisions. Final say over family matters may lead some women to feel powerful, whereas for others it may bring an endless second shift (Hochschild and Machung 1989). As men and women's time allocations converge, measures of gender inequality within families beyond differences in unpaid labor become imperative (Bianchi et al. 2012). While both men and women work outside the home, women may be called upon to participate in family decisions whether they share the decision responsibility with their male partners (Equality or Bust) or if they are expected to make 


\section{Final Say}

them on their own. Increases in men's willingness to participate in unpaid family labor, housework and childcare, does not seem to translate into increased responsibility for family decisions (Knudsen and Wærness 2009). This behavior may parallel men's responsibility for providing financially for their families, even when men share the financial responsibility with their female partners. Overall, these findings are consistent with research showing commitment to beliefs in egalitarian essentialism, that women and men are equal but characteristically

different (Cotter et al. 2011). In sum, 'final say' measures should be used with great caution as measurements of power. 
Final Say

\section{REFERENCES}

Becker, Gary S. 1974. “A Theory of Marriage.” Pp. 299-343 in Economics of the Family, edited by Theodore W Schultz. Chicago: University Of Chicago Press.

Belch, Michael A., and Laura A. Willis. 2002. "Family Decision at the Turn of the Century: Has the Changing Structure of Households Impacted the Family Decision-Making Process?” Journal of Consumer Behaviour 2:111-24.

Bennett, Fran. 2013. "Researching Within-Household Distribution: Overview, Developments, Debates, and Methodological Challenges.” Journal of Marriage and Family 75:582-97.

Bianchi, Suzanne M., Liana C. Sayer, Melissa A. Milkie, and John P. Robinson. 2012. “Housework: Who Did, Does or Will Do It, and How Much Does It Matter?” Social Forces 91:55-63.

Bittman, Michael, Paula England, Liana Sayer, Nancy Folbre, and George Matheson. 2003. "When Does Gender Trump Money? Bargaining and Time in Household Work." American Journal of Sociology 109:186-214.

Blood, Robert O., and Donald M. Wolfe. 1960. Husbands \& Wives: The Dynamics of Married Living. Glencoe, IL: Free Press.

Blumberg, Rae Lesser, and Marion Tolbert Coleman. 1989. “A Theoretical Look at the Gender Balance of Power in the American Couple.” Journal of Family Issues 10:225-50.

Blumstein, Philip, and Pepper Schwartz. 1983. American Couples: Money, Work, Sex. New York: William Morrow \& Co.

Brines, Julie. 1994. "Economic Dependency, Gender, and the Division of Labor at Home." American Journal of Sociology 100:652-88. 
Final Say

Brooks-Gunn, Jeanne, Irwin Garfinkel, Sara S. McLanahan, and Christina Paxson. 2011. Fragile Families and Child Wellbeing Study [Public Use Data]. ICPSR31622-v1. Ann Arbor, MI: Inter-University Consortium for Political and Social Research [Distributor]. Retrieved (http://doi.org/10.3886/ICPSR31622.v1).

Burgoyne, Carole. 2004. "Heart-Strings and Purse-Strings: Money in Heterosexual Marriage.” Feminism \& Psychology 14:165-72.

Burgoyne, Carole B. 1990. "Money in Marriage: How Patterns of Allocation Both Reflect and Conceal Power." Sociological Review 38:634-65.

Burgoyne, Carole B., Victoria Clarke, Janet Reibstein, and Anne Edmunds. 2006. “"All My Worldly Goods I Share with You'? Managing Money at the Transition to Heterosexual Marriage." The Sociological Review 54:619-37.

Cherlin, Andrew J. 2009. "How American Family Life Is Different.” in The Marriage-GoRound: The State of Marriage and the Family in America Today. New York: Alfred A. Knopf.

Cohen, Philip N. 2014. The Family: Diversity, Inequality, and Social Change. New York: W. W. Norton \& Company.

Coltrane, Scott. 1996. Family Man: Fatherhood, Housework and Gender Equity. New York: Oxford University Press.

Corbin, Juliet, and Anselm Strauss. 2008. Basics of Qualitative Research: Techniques and Procedures for Developing Grounded Theory. 3rd ed. SAGE Publications, Inc.

Cotter, David A., Joan M. Hermsen, and Reeve Vanneman. 2011. "The End of the Gender Revolution? Gender Role Attitudes from 1977 to 2008.” American Journal of Sociology $117: 259-89$. 
Final Say

DeNavas-Walt, Carmen, and Bernadette D. Proctor. 2015. Income and Poverty in the United States: 2014. Washington, D.C: U.S. Census Bureau. Retrieved September 13, 2016 (https://www.census.gov/content/dam/Census/library/publications/2015/demo/p60252.pdf).

Fairclough, Norman, ed. 1995. Critical Discourse Analysis: The Critical Study of Language. New York: Longman Group Limited.

Farrell, Allison K., Jeffry A. Simpson, and Alexander J. Rothman. 2015. "The Relationship Power Inventory: Development and Validation.” Personal Relationships 22:387-413.

Ferree, Myra Marx. 1990. "Beyond Separate Spheres: Feminism and Family Research.” Journal of Marriage and Family 52:866-84.

Freese, Jeremy, and James Druckman. 2016. "Data Collected by Time-Sharing Experiments for the Social Sciences, NSF Grant 0818839.”

Galliher, Renee V., Sharon S. Rostosky, Deborah P. Welsh, and Myra C. Kawaguchi. 1999. "Power and Psychological Well-Being in Late Adolescent Romantic Relationships." Sex Roles 40:689-710.

Gramsci, Antonio. 1971. Selections from the Prison Notebooks. edited by Quintin Hoare and Geoffrey Nowell Smith. New York: International Publishers Co.

Gupta, Sanjiv. 2007. “Autonomy, Dependence, or Display? The Relationship between Married Women's Earnings and Housework." Journal of Marriage and Family 69:399-417.

Harris, Katherine Mullan et al. 2009. The National Longitudinal Study of Adolescent to Adult Health: Research Design [WWW Document]. Retrieved (http://www.cpc.unc.edu/projects/addhealth/design.). 
Final Say

Hochschild, Arlie Russell, and Anne Machung. 1989. The Second Shift. New York: Penguin Books.

Hsiao-Li, Shirley Sun. 2010. “The 'Final Say’ Is Not the Last Word.” Journal of Comparative Research in Anthropology \& Sociology 1:91-105.

ISSP Research Group. 2014. Family and Changing Gender Roles IV Variable Report. GESIS Leibniz Institute for the Social Sciences Unter Sachsenhausen.

Kenney, Catherine T. 2006. "The Power of the Purse: Allocative Systems and Inequality in Couple Households." Gender \& Society 20:354-81.

Knudsen, Knud, and Kari Wærness. 2009. "Shared or Separate? Money Management and Changing Norms of Gender Equality among Norwegian Couples.” Community, Work \& Family 12:39-55.

Komter, Aafke. 1989. "Hidden Power in Marriage.” Gender and Society 3:187-216.

Lieberson, Stanley. 2000. A Matter of Taste: How Names, Fashions, and Culture Change. New Haven: Yale University Press.

Mizan, Ainon N. 1994. "Family Power Studies: Some Major Methodological Issues.” International Journal of Sociology of the Family 24:85-91.

Moore, Mignon R. 2008. “Gendered Power Relations among Women: A Study of Household Decision Making in Black, Lesbian Stepfamilies.” American Sociological Review 73:335-56.

Pew Research Center. 2008. Women Call the Shots at Home; Public Mixed on Gender Roles in Jobs. Washington, D.C. Retrieved January 3, 2017 (http://www.pewsocialtrends.org/2008/09/25/women-call-the-shots-at-home-publicmixed-on-gender-roles-in-jobs/). 
Final Say

Pyke, Karen D. 1994. “Women’s Employment as a Gift or Burden?: Marital Power across Marriage, Divorce, and Remarriage." Gender and Society 8:73-91.

Ridgeway, Cecilia L., and Lynn Smith-Lovin. 1999. “The Gender System and Interaction.” Annual Review of Sociology 25:191-216.

Roman, Christine, and Carolyn Vogler. 1999. "Managing Money in British and Swedish Households.” European Societies 1:419-56.

Schwartz, Pepper. 1994. Love Between Equals: How Peer Marriage Really Works. New York: Free Press.

Simpson, Jeffry A., Allison K. Farrell, M. M. Oriña, and Alexander J. Rothman. 2015. “Power and Social Influence in Relationships.” Pp. 393-420 in APA Handbook of Personality and Social Psychology: Interpersonal Relations, edited by Jeffry A. Simpson and J.F. Dovidio. Washington, D.C: American Psycchological Association.

Thibaut, John W., and Harold H. Kelley. 1959. The Social Psychology of Groups. Oxford, England: John Wiley.

Tichenor, Veronica Jaris. 1999. "Status and Income as Gendered Resources: The Case of Marital Power." Journal of Marriage and Family 61:638-50.

Townsend, Nicholas. 2002. Package Deal: Marriage, Work And Fatherhood In Men's Lives. Philadelphia: Temple University Press.

Vogler, Carolyn, and Jan Pahl. 1994. “Money, Power and Inequality within Marriage.” Sociological Review 42:263-88.

Walzer, Susan. 1998. Thinking about the Baby: Gender and Transitions into Parenthood. Philadelphia, PA: Temple University Press. 
Final Say

\section{END NOTES}

${ }^{i}$ Three respondents selected a partial-pooling approach for the fictional couple but in a follow-up question divided the earnings into an all individual or an all shared approach. Because these respondents' intentions cannot be discerned from their contradictory answers, they were dropped from the analysis.

ii The marital status, parental status, and relationship duration of the fictional couples were manipulated for a different study. These manipulation makes no difference in the conclusions drawn from the analyses in this study whether or not they are included in the models.

iii Pilot tests of the vignette showed respondents assumed the couple's racial identity was either white or the same as their own race.

iv Some studies have highlighted problems with interpreting interaction effects using logistic regression. Models using OLS regression do not change the conclusions of this article.

${ }^{v}$ Analysis not shown indicate that not collapsing the scale produces similar results and does not change the main conclusions of this paper. The dichotomous presentation of the results provides for easier interpretation and thus were chosen to display the findings.

${ }^{\text {vi }}$ Items and activities were manipulated to ensure responses were not dependent on the item or activity under consideration. In analysis not shown, within item (mattress, house, or vacation) and activity (mattress, house, or vacation) groups, there was no variation in perceptions of fairness based on the item or activity manipulation. 